\title{
CORRECTION TO THE NOTE \\ ON RAPIDLY MIXING TRANSFORMATIONS AND AN APPLICATION TO CONTINUED FRACTIONS
}

\author{
BY M. KAC AND HARRY KESTEN \\ Communicated November 6, 1958
}

After our note has been printed it has come to our attention that our result on continued fractions is already contained in a paper by W. Doeblin, Remarques sur la théorie métrique des fractions continues, Compositio Math. vol. 7 (1940) pp. 353-371.

We regret that this important paper escaped our notice and we can only hope that it will become more widely known than it apparently is.

\section{REFERENCE}

1. M. Kac and Harry Kesten, On rapidly mixing transformations and an application to continued fractions, Bull. Amer. Math. Soc. vol. 64 (1958) pp. 283-287.

CORNELl UNIVERSITY AND

Princeton University 